\title{
The Impact and Effectivness of the World Bank's Health VII Medical Financial Assistance Project
}

Wei Zhong

\section{(2) OpenEdition}

12 Journals

Electronic version

URL: http://journals.openedition.org/chinaperspectives/3773

DOI: 10.4000/chinaperspectives.3773

ISSN: 1996-4617

Publisher

Centre d'étude français sur la Chine contemporaine

\section{Printed version}

Date of publication: 4 April 2008

Number of pages: $76-81$

ISSN: 2070-3449

\section{Electronic reference}

Wei Zhong, «The Impact and Effectivness of the World Bank's Health VII Medical Financial Assistance Project », China Perspectives [Online], 2008/2 | 2008, Online since 01 April 2011, connection on 28 October 2019. URL : http://journals.openedition.org/chinaperspectives/3773 ; DOI : 10.4000/

chinaperspectives.3773 
(1)

The Impact and Effectiveness

of the World Bank's Health

VIII Medical Financial

\section{Assistance Project}

WEI ZHONG

$66 \pi$ edical financial assistance" (MFA) refers to special help and support provided by the gov-

ernment and society to those among the poor who are unable to meet the cost of medical treatment when they are ill. It is an important component of the social insurance system. Although a medical financial assistance system has long been an organic part of the social security systems of many developed nations, in China it is still something new. ${ }^{(1)}$

Medical financial assistance has emerged and developed as China's society and economy have developed, and is linked in particular to changes in the healthcare system. From the 1950s to the 1970s, a co-operative healthcare system, largely the responsibility of the collective economy, was in place in China's rural areas. Following the disintegration of this cooperative healthcare system during the Cultural Revolution, and the transformation of the public health system into a medical insurance system once the period of reform and opening began, the difficulties experienced by the rural poor in accessing medical care became very apparent. This led the relevant authorities, with the assistance of international organisations and non-governmental organisations, to introduce medical financial assistance pilot schemes in a few rural areas. ${ }^{(2)}$ However, in the 1980s and 1990s, the concept of medical financial assistance and methods of implementation were mentioned only occasionally in government documents dealing with poverty relief or the strengthening of primary-level health care in rural areas, and it was not on the agenda for some time. Not until 2002, with the publication of the State Council's Resolution on further strengthening rural health work, was medical financial assistance given any recognition in an official document.

\section{Design of the Health VIII medical financial assistance project}

Well before the central government's document concerning this project was issued, the Ministry of Health had already, with the support of relevant international organisations, begun to implement some experimental medical assistance schemes for the very poor in rural areas. The best-known and the largest of these experiments was the "Medical Financial Assistance Project for the Rural Poor," part of the China Basic Health Services Project (Health VIII), which was carried out by the World Bank, the United Kingdom's Department for International Development, the Ford Foundation, and the American-Chinese Foundation, in co-operation with the Ministry of Health. ${ }^{(3)}$

The aim of the project was "to improve health service capacity in poor areas and increase the level of health service utilization, to ensure that the residents in those areas had access to basic medical and health services, and to bring about sustainable improvements in health for people in poor rural

1. Wu Qunhong, Zhang Zhenzhong, and Liu Yunguo, "Guanyu Zhongguo jianli tekun renkou yiliao jiuzhu zhidu de biyaoxing tantao" (On the need to establish medical financial assistance for the extremely poor in China), Zhongguo nongcun weisheng shiye guanli (Chinese rural health service administration), Vol. 21, No. 6, 2001. Zhang Zhenzhong, "Zai Zhongguo nongcun jianli pinkun renkou yiliao jiuzhu zhidu yanjiu" (On the establishment of MFA for the poor in rural China), Zhongguo weisheng jingji (Chinese health economics), Vol. 21, No. 11, 2002.

2. Han Leiya and Zhang Zhenzhong, "Dui pinkun renkou shishi yiliao jiuzhu" (Implementing medical financial assistance for the poor), Zhongguo weisheng jingji (Chinese health economics), $\mathrm{n}^{\circ} 11,1999$.

3. Liu Yunguo and Shen Shuanghong, 'Shijie yinhang daikuan 'Weisheng VIII' xiangmu gaikuang yu jinzhan" (Survey of, and progress in, the World Bank-funded 'Health VIII' programme), in Weisheng jingji yanjiu (Health economics research), №. 9, 1999. 
tered according to their degree of poverty. The committee decided the initial list of participating households on the basis of the quota allocated, then posted the list for the whole village to see, or revised it on the basis of other information received. The report forms were then completed by the village committee staff and submitted to the township government. The township government collectively examined and appraised the report forms, then sent them to the county Health VIII project office. When the forms had been examined, verified, and stamped by the county project office, the township government issued MFA cards to those households targeted for assistance. After that, the township authorities concerned would carry out annual checks, in the same sequence, on the MFA beneficiaries in the township and make any necessary adjustments. ${ }^{(5)}$

\section{The effects of the project on ac-} cess to medical services and existing problems

According to both the principles of MFA and the project design, MFA is supposed to be assistance provided to the poor. But our survey ${ }^{(6)}$ shows that selection of the MFA target families was clearly influenced by local residents' understanding of the scheme and by local politics, and almost half (46.5 percent) of the group covered by MFA were not in fact poor families. Of those people who were covered by MFA, the proportion of families containing members who were ill but whose incomes were above the poverty line was 37.5 percent, much higher than the proportion of poor families in which nobody was ill, and this indicated that the villagers had an inadequate understanding of MFA. What is more, 8.9 percent of the families covered contained no ill members and were not poor, and one cannot but conclude that this was due to the influence of local politics.

In spite of the emergence of problems of this kind, the degree of transparency in the process of identifying those targeted for MFA on the whole ensured that the project could cover more families who either met the requirements of the design of the system or had been approved by the residents in their rural communities, and compared to other systems of assistance that lack such transparency, the selection process was considered generally acceptable. There were still marked discrepancies between the families covered by MFA and the families not covered by it in many fundamental aspects. There were, for example, a relatively large number of elderly people in the group covered by MFA, and quite a high proportion of adults who were confined to bed for a long period and unable to work. This means that the MFA group included more people who were likely to make greater use of higher-level medical services. However, the distribution of occupational characteristics in the different groups suggests that the proportion of people in non-MFA groups who were engaged in non-agricultural occupations was clearly higher than in MFA groups, while for MFA groups quite the reverse was true; not only was there a higher proportion of people employed in agriculture, forestry, animal husbandry, and fishing, but the proportion of people not working, in particular the disabled and the elderly, was also quite high.

Certain disparities also existed between the two groups for the indices reflecting household economic conditions. A whole series of indices were better for the non-MFA groups than for the MFA groups: the per capita net income of family members in the non-MFA groups was 1.7 times that of the MFA groups, and they owned 2.4 as much real estate and 1.3 times as much farm-land; as a negative index of income, in 2004 the MFA groups were 1.9 times more likely to have borrowed money due to illness than the non-MFA groups. This information indicates that those targeted by MFA included groups who were economically vulnerable as well as those who were vulnerable because of health problems. But because there were limits on the proportion of the population to be assisted, and because the distribution of indicators in the rural areas was not altogether rational, some economically vulnerable people and people in poor health were still excluded from the MFA project.

For a health service provider, the quality of its capacity for service provision also directly affects the outcome of the implementation of the system. We discovered from the questionnaires that we sent to village health service institutions that village-level health service institutions in central and western China have the capacity to provide routine health services, such as intravenous injections, intravenous drips, diagnosis by stethoscope, routine vaccinations, etc. But there remains a fairly urgent problem, in that the capacity of these village-level health service institutions to handle some quite common emergencies is still inadequate, particularly with regard to haemostasis, suturing, wound-dressing, fixing frac-

5. Zheng Xiangtao and Wu Ruixue, "Nongcun yiliao jiuzhu tixi cunzai de wenti ji qi wanshan silu" (Some issues in the system of rural medical financial assistance and thoughts on how to improve and perfect it), in Weisheng jingji yanjiu (Health economics research), No. 4, 2005.

6. Sample data in this report come from a survey of the livelihood and health situation of agricultural households in six MFA project counties in central and western China carried out by the CASS Institute of Economics in 2005 . 

county-level or above with a greater service capacity (14.8 percent). But with the effects of the co-operative health system and the design of the MFA system, more families covered by health insurance chose to go to township health centres (38.1 percent). Thus the design of systems such as MFA has had a distorting effect on choice of medical institution.

\section{Functional analysis of MFA in combating the risk of serious illness}

In a developing nation with a limited financial capacity, the accumulation of funds for social medical insurance or medical financial assistance is a huge problem, and one that China must inevitably confront. With limited funds, China's health policy makers have always been faced with the dilemma of whether to prioritise insurance for major illnesses and thus reduce the impact illness has on families, or to prioritise insurance for minor illnesses and thus obtain support from more families in building up funds. As a medical assistance scheme principally geared toward the poor, it also attracted our attention because it manifests itself in combating the risk of serious illnesses.

Firstly, constrained as it was by household economic conditions, the design of the MFA project has influenced the choice of medical institution made by people suffering from serious illnesses. One positive manifestation of this is that when having to deal with a serious illness, many more peasant households in receipt of MFA chose to see a doctor than families that were not covered (only 7.6 percent of MFA households did not go to a medical institution, whereas the proportion of non-MFA families was 16.9 percent). But because more of those covered were from poor families who are more likely to take economic factors into consideration when faced with serious illness, the MFA families more often chose to go to first-level township health centres (66.9 percent of MFA households as opposed to 39.3 percent of the other group), and they less often chose to go to the more expensive medical institutions at county level and above (37.3 percent of MFA households compared to 66.1 percent of non-MFA households). If we then take into account the fact that the design of the system is such that the township health centre claims ratios adopted by almost all the project counties are high, and that the claims ratio of medical institutions at county-level and above is low, it is very clear that the MFA has exacerbated the consideration of economic factors when rural households are faced with serious illness and have to make a choice about where to seek medical care.

Our statistical analysis threw up an anomaly with regard to cures from illness, in which the overall cure rate for the MFA group (20.7 percent) was lower than that for the nonMFA group (29.2 percent). When we analysed the groups according to the institutions they chose to visit for medical care, we found that the cure rate for the MFA group was equal to or even slightly better than that for the non-MFA group if care was obtained from county-level or other medical institutions; but if they went to township or central clinics, the MFA group cure rate was far lower than that of the non-MFA group.

In order to explain the lower cure rate from serious illnesses for MFA beneficiaries, we need to look at history, economics, and the system design. Firstly, the system relief effect. Because there had been virtually no health insurance coverage for a long period in the past, let alone an MFA project specifically targeting the poor, the majority of the illnesses from which this sector of the population suffered had built up over a long period and were harder to cure in comparison with other groups. Secondly, the effects of social economic conditions. Even with the MFA project, most of those covered belonged to the lower socio-economic level, and were still unable to afford the high medical bills they needed to pay in order to be restored to health. This meant that therapeutic efficacy was poor. Thirdly, reasons connected with system design. Because it took into account the fees charged, the design of the MFA system focused on the first-level township health centres, which meant that more people covered by MFA but who needed better therapeutic conditions were concentrating in these health centres for treatment. However, it is clear that the therapeutic efficacy of these township health centres for this group is poor, even when compared with the non-MFA group.

Therefore, a resolution of the problem will depend on finding a way for medical financial assistance to give beneficiaries access to hospitals at county-level and above, and raising the service capacity of first-level township medical centres as quickly as possible.

\section{Findings and conclusion}

The findings of this paper can be summed up under three main points:

1) The group covered by MFA contained both poor people and people in poor health, and there was a diver- 
gence between those people targeted for cover and the objectives of the system as designed.

2) The project helped to improve the uptake of medical services by the poor, especially their utilization of township health centres.

3) MFA helped reduce the financial burden of sickness on poor families and prevented the marginalization of communities, families, and individuals put at risk by catastrophic illness. However, because the illnesses suffered by the beneficiaries are often serious and complex, and recovery from them is difficult, the amount of assistance provided is still small when compared to the medical costs. In addition, the system of assistance now in operation plays no noticeable role in helping the sufferer recover his/her earning capacity. As the MFA project is not yet adequate to prevent those who become poor in the short-term from becoming poor in the long-term, it is difficult to prevent relatively low-level poverty from turning into deep poverty.

Since 2003, a rural medical assistance programme instituted by the central Chinese government has been rolled out na- tion-wide, and it was reported that 87 percent of the counties in China had established such programmes by the end of 2006. From a comparison of the rural medical assistance programmes promoted by departments in the administration and by MFA, it is evident that the former have absorbed much of the design of the latter, and lessons have been learned from the experience of MFA implementation. ${ }^{(8)} \mathrm{We}$ can therefore say that the MFA project has served as an invaluable model for the Chinese government's establishment of medical financial assistance schemes nation-wide. Of course, since so much of the MFA project design has been used as a reference, it is inevitable that the problems originally present in this project will be carried over into China's current process of implementing a health assistance system. For that reason, investigating and summing up the MFA project in greater depth might be a very valuable exercise. •

\section{- Translated by Caroline Mason}

8. Wu Ming, Zhang Zhenzhong, Zhao Kun, Huang Chunfang, Cui Bin, Wang Huihui and XinYing, "Zhongguo nongcun pinkun yiliao jiuzhu jiance yu pingjia zhibiao tixi de lilun kuangjia yanjiu" (A survey of medical financial assistance for the poor in rural China and the theoretical framework of the system of evaluation indicators), in Zhongguo weisheng ziliao (Chinese health data), Vol. 7, No. 3, 2004. 